\title{
Correction to: Adduct annotation in liquid chromatography/high-resolution mass spectrometry to enhance compound identification
}

\author{
Thomas Stricker $^{1,2} \cdot$ Ron Bonner $^{3} \cdot$ Frédérique Lisacek $^{2} \cdot$ Gérard Hopfgartner $^{1}$
}

Received: 22 December 2020 / Accepted: 22 December 2020 / Published online: 12 January 2021

(C) Springer-Verlag GmbH Germany, part of Springer Nature 2021

\section{Correction to: Analytical and Bioanalytical Chemistry} https://doi.org/10.1007/s00216-020-03019-3

The authors would like to call the reader's attention to the fact that, unfortunately, there was a spelling mistake regarding the name of one of the authors in this manuscript; please find the correct information below

Frédérique Lisacek

Publisher's note Springer Nature remains neutral with regard to jurisdictional claims in published maps and institutional affiliations.

The online version of the original article can be found at https://doi.org/ 10.1007/s00216-020-03019-3

Gérard Hopfgartner

gerard.hopfgartner@unige.ch

1 Life Sciences Mass Spectrometry, Department of Inorganic and Analytical Chemistry, University of Geneva, 24 Quai Ernest Ansermet, 1211 Geneva 4, Switzerland

2 Proteome Informatics Group (PIG), Swiss Institute of Bioinformatics and University of Geneva, 7, route de Drize, 1211 Geneva 4, Switzerland

3 Ron Bonner Consulting, Newmarket, ON L3Y 3C7, Canada 